\title{
A Contribuição de Thomas Kuhn para a Produção Científica em Administração
}

Silvana Anita Walter ${ }^{1}$

Daniela Torres da Rocha ${ }^{2}$

\section{Resumo}

Este estudo objetiva analisar como os conceitos desenvolvidos por Kuhn, na obra A estrutura das revoluções científicas, têm e podem contribuir com os estudos da área de administração. Outro objetivo consiste em verificar se a área de administração emprega o termo paradigma conforme o sentido atribuído por Kuhn. Realizou-se uma pesquisa bibliográfica e bibliométrica nos estudos do EnANPAD, de 1997 a 2007. Observou-se, nos 66 estudos encontrados com citações de Kuhn (1962), que as áreas do EnANPAD que possuem mais artigos citando o autor são a de ensino e pesquisa e a de estudos organizacionais. Constatou-se que a maioria dos estudos revisados emprega o termo paradigma conforme o sentido atribuído por Kuhn (1962), e que os conceitos mais citados são: revolução científica, paradigma, fase pré-paradigmática e ciência normal. Identificou-se como tais conceitos estão contribuindo com a administração, principalmente no que se refere ao entendimento de características dessa área de estudo.

Palavras-chave: Thomas Kuhn. A Estrutura das revoluções científicas. Paradigma.

\section{Introdução}

Thomas S. Kuhn nasceu em 18 de julho de 1922, em Cincinnati, no estado de Ohio, Estados Unidos, e faleceu em 1996. Ingressou, em 1940, na Universidade de Harvard, para estudar Física. Em 1949, doutorou-se em Fí-

\footnotetext{
${ }^{1}$ Doutora em Administração pela Pontifícia Universidade Católica do Paraná-PUC/PR. Professora do Programa de Pós-Graduação em Administração da Universidade Regional de Blumenau - FURB. End.: Rua Paulo Zimmermann, 85, Centro, Blumenau -SC. CEP: 89010-170 - Brasil. E-mail: silvanaanita.walter@gmail.com.

${ }^{2}$ Doutoranda em Administração pela Pontifícia Universidade Católica do Paraná - PUC/PR. End.: Rua Imaculada Conceição, 1155, Prado Velho, Curitiba-PR. CEP: 80215-901 - Brasil.E-mail: danitorres.rocha@gmail.com.

Artigo recebido em: 21/06/2010. Aceito em: 05/04/2011. Membro do Corpo Editorial Científico responsável pelo processo editorial: Thomas G. Brashear.

(c) (i) $\ominus$ Esta obra está sob uma Licença Creative Commons Atribuição-Uso.
} 
sica, chegando a publicar um artigo nessa área. Posteriormente, consolidou sua saída da Física, passando a se dedicar à história e à filosofia da ciência. Em 1956, mudou-se para o Departamento de Filosofia da Universidade da Califórnia, em Berkeley, onde permaneceu até 1964 e onde, a partir de 1961, concebeu e desenvolveu, auxiliado por Paul Forman e John Heilbron, um projeto de documentação da história da mecânica quântica. Em 1964, com o término desse projeto, transferiu-se, como professor de Filosofia, para a Universidade de Princeton, lá permanecendo até 1979. A partir daí, se tornou professor em Harvard (MENDONÇA; VIDEIRA, 2002).

As ideias de Thomas Kuhn sobre como as ciências evoluem são discutidas desde 1962, a partir do seu livro The structure of scientific revolutions - a estrutura das revoluções científicas -, lançado no Brasil em 1976. Em sua obra, Kuhn apresenta sua concepção sobre o desenvolvimento da ciência e expõe os principais conceitos de sua teoria: ciência normal, paradigma e revolução científica. Kuhn descreve o paradigma como uma realização científica que se torna modelo para as demais pesquisas daquela área; a ciência normal, como o período em que tal paradigma permanece vigente na ciência e no qual são realizados estudos para aperfeiçoamento desse paradigma; e a revolução científica como o momento de crise no qual o paradigma vigente é substituído por um novo paradigma mais eficiente (KUHN, 1962).

Para Bertero, Caldas e Wood Jr. (1998), os conceitos de Kuhn são muito importantes para a área de administração. Segundo os autores,

Para a administração [...] o espaço científico mais expressivo que se consolidou no pensamento ocidental foi feito exatamente com a utilização do que Thomas Kuhn chamou de "ciência normal". (BERTERO; CALDAS; WOOD Jr., 1998p. 3).

Isso porque, apesar de, ao escrever sua obra, Kuhn tenha voltado suas reflexões às ciências exatas, é impossível negar que seus apontamentos exercem grande influência sobre áreas como a administração, consideradas novas em relação a outras ciências (BERTERO; CALDAS; WOOD Jr., 1998).

Anteriormente à obra A estrutura das revoluções científicas, Kuhn, em 1957, publicou outro livro que foi precursor da discussão deste autor a respeito do desenvolvimento da ciência: The Copernican Revolution. Nessa 
obra, Kuhn (1957) apontava que o sistema Copernicano somente era mais adequado do que o Ptolemaico em seus aspectos qualitativos, pois, nos aspectos quantitativos, o primeiro necessitava do aparato de epiciclos e deferentes, empregado no sistema Ptolemaico. Assim, para ele, existiam poucas (ou nenhuma) razões para realizar a escolha entre os dois modelos. Dessa forma, nota-se que Kuhn (1957) já adiantava sua perspectiva sobre a escolha de paradigmas, a qual seria ampliada em sua obra de 1962.

Diante do exposto, procurar-se-á responder à seguinte pergunta de pesquisa: Como os conceitos desenvolvidos por Kuhn têm contribuído e como podem contribuir com os estudos da área de administração? Partindo dessa questão, tem-se o objetivo de analisar como os conceitos desenvolvidos por Kuhn na obra A estrutura das revoluções científicas têm contribuído e como podem contribuir com os estudos da área de administração. Um objetivo complementar consiste em verificar se a área de administração costuma empregar o termo paradigma em acordo com o conceito proposto por Kuhn. Para tanto, se optou por realizar uma avaliação dos estudos da área de administração publicados nos anais do EnANPAD, de 1997 a 2007, por meio da qual se buscou identificar aqueles que citam a obra A estrutura das revoluções científicas, de Thomas Kuhn. Dessa forma, verifica-se a influência desta obra de Kuhn no período de 20 a 30 anos após seu lançamento no país.

Os resultados obtidos estão assim estruturados neste artigo: na Seção 2, apresenta-se os principais apontamentos de Kuhn na obra A estrutura das revoluções científicas; na Seção 3, a metodologia empregada; na Seção 4, as análises feitas a partir dos estudos encontrados que citam a referida obra; $e$, na Seção 5, as considerações finais.

\section{Revisão de Literatura}

Nesta seção, apresentam-se os principais apontamentos de Kuhn presentes na obra A estrutura das revoluções científicas (KUHN, 1962): ciência normal e paradigma; metáfora do quebra-cabeça; períodos de crise e períodos pré-paradigmáticos; revolução científica; progresso da ciência; vantagens da ciência normal; e a ciência não é cumulativa. 


\subsection{Ciência Normal e Paradigma}

Dois dos principais conceitos apresentados por Kuhn (1962) são os de ciência normal e de paradigma. O primeiro se fundamenta em realizações científicas anteriores e o segundo consiste em uma realização científica que se torna modelo para as demais pesquisas daquela área. Esses dois conceitos estão interligados, uma vez que, segundo Kuhn (1962), pesquisadores que atuam em um mesmo paradigma compartilham regras e padrões comuns para suas pesquisas, o que é visto como um requisito para a ciência normal.

Ainda de acordo com Kuhn (1962), a adoção de um paradigma é um sinal de que o tipo de pesquisa está amadurecido, porque, ao longo de sua história, as teorias concorrentes foram substituídas por uma teoria comum, ocasionando o desaparecimento das divergências iniciais existentes entre os pesquisadores. Essas pesquisas se caracterizam, também, por conseguirem adesão de um grande grupo de partidários.

Quando um paradigma é adotado, sob a ótica de Kuhn (1962), todas as teorias pré-existentes na área desaparecem, e os pesquisadores que não concordam com o paradigma são excluídos e têm seus trabalhos ignorados. Entretanto, podem continuar produzindo, o que Kuhn (1962) chama de ciências especiais.

Assim, a ciência normal foca aspectos apontados pelo paradigma e trabalha com operações de limpeza que, para Kuhn (1962), consistem em tentar enquadrar a natureza nas linhas do paradigma. Isso porque, segundo Kuhn (1962), alguns paradigmas não são claros em relação aos campos e formas de aplicação, surgindo a necessidade de novas pesquisas para tais definições. Kuhn (1962) aponta que a maioria dos trabalhos da ciência normal objetiva a reformulação de paradigmas, procurando produzir mudanças que clarifiquem sua definição e a tornem mais coerente e uniforme, visto serem caracteristicamente abertas e deixarem uma grande espécie de problemas a serem resolvidos pelos praticantes daquela ciência.

Para Kuhn (1962), a pesquisa normal se caracteriza como cumulativa porque seleciona fenômenos que podem ser respondidos por meio de técnicas já existentes. No entanto, segundo o autor, é difícil defender o desenvolvimento cumulativo, porque não é possível dizer que a ciência evolui de uma teoria inferior para uma superior, uma vez que há, na história científica, exemplos de cientistas que recorreram a teorias anteriores para explicar fenômenos. 


\subsection{A Metáfora do Quebra-Cabeça}

Para explicar a motivação que leva o pesquisador a trabalhar com a ciência normal, Kuhn (1962) cita a metáfora do quebra-cabeça. Quebra-cabeças, para Kuhn (1962), são problemas que testam a habilidade da pessoa para encontrar sua resolução. Sendo assim, o desafio do cientista normal é trabalhar na resolução de quebra-cabeças. Essa motivação se dá pelo fato de que o quebra-cabeça possui uma resolução possível que até então ninguém encontrou e que o pesquisador, por meio de sua habilidade, se suficiente, a encontrará.

Ainda se utilizando da metáfora do quebra-cabeça, Kuhn (1962) assevera que tanto a ciência normal quanto o quebra-cabeça possuem regras que limitam os passos para chegar a uma resolução, bem como às resoluções aceitáveis. De acordo com Kuhn (1962), a relação da ciência normal com a resolução de quebra-cabeças é consolidada pela existência de compromissos dos cientistas. Um desses compromissos relaciona-se aos instrumentos que proporcionam as regras do jogo; outros são metafísicos e metodológicos; e outros, ainda, se preocupam em investigar, com precisão e atenção à ordem vigente, aspectos da natureza.

Kuhn (1962) ressalta que as regras surgem de paradigmas, mas que os paradigmas podem direcionar as pesquisas mesmo sem regras e que a ciência normal é amplamente determinada por regras, mas não necessariamente em sua totalidade.

Todavia, os problemas que a ciência normal considera como quebracabeças podem ser vistos como contraexemplos (ou anomalias) e, assim, fontes de crise. Quando a resolução dos quebra-cabeças da ciência normal não é possível, ela permite o surgimento de novos paradigmas (KUHN, 1962).

\subsection{Períodos de Crise e Períodos Pré-Paradigmáticos}

Para Kuhn (1962), nas pesquisas de ciência normal, os pesquisadores apresentam desinteresse em produzir novidades. Para esse autor, o objetivo da ciência normal não é produzir tais novidades, mas aumentar a precisão $e$ o alcance do paradigma. Ainda segundo o autor, caso os cientistas não cheguem, em suas pesquisas, a um resultado próximo ao do paradigma, esse resultado será considerado fracasso pessoal. Em contrapartida, quando uma descoberta acontece e é incorporada à ciência, altera o empreendimento ci- 
entífico. De acordo com Kuhn (1962), esse tipo de descoberta é chamado de anomalia, pois viola as expectativas do paradigma que regiam a ciência normal. Essa violação das expectativas provoca uma crise na ciência normal, visto que, mesmo com uma série de aperfeiçoamentos, um paradigma não obtém resultados satisfatórios e não explica as anomalias, ou seja, tem-se um fracasso dos quebra-cabeças da ciência normal no alcance de resultados $e$ necessita-se de um novo paradigma.

Kuhn (1962) descreve como ocorre o processo de crise mencionado: quando uma anomalia resiste por um período considerável, muitos cientistas passam somente a pesquisá-la e, assim, seu campo de estudo se altera. Os ataques ao problema não resolvido, por sua vez, conduzirão a inúmeras e diferentes articulações do paradigma que, no entanto, não atingem sucesso suficiente para serem consideradas como paradigma. Assim, ao longo desse processo, o paradigma perde sua definição, e os cientistas não concordarão sobre o que ele é e suas soluções. Para esse período de crise, segundo Kuhn (1962), existem três resoluções: a ciência normal pode solucionar o problema que acarretou a crise; o problema pode ser deixado para que as que novas gerações o solucionem; ou pode surgir um candidato ao paradigma.

Para Kuhn (1962), a importância atribuída a uma crise variará conforme a ruptura que ela estabelecer no paradigma. Kuhn (1962) indica o exemplo da descoberta do oxigênio que acarretou uma mudança no paradigma da teoria flogística. Segundo o autor, essa descoberta isoladamente não foi a causa da mudança do paradigma, uma vez que um dos cientistas que realizou a descoberta, Lavoisier, anteriormente já questionava tal paradigma. Ainda em relação a esse exemplo, Kuhn destaca que houve a necessidade de uma revisão no paradigma para que fosse possível compreender o fenômeno da mesma maneira que Lavoisier, visto que o paradigma precisou ser alterado para que a anomalia se transformasse no esperado e se tornasse científico, ou seja, se transformasse em um novo paradigma.

Sob a ótica de Kuhn (1962), os períodos pré-paradigmáticos pedem a refutação do conhecimento anterior para o estabelecimento de um novo conhecimento, ou seja, consiste no período de crise anterior à consolidação de um paradigma. Somente nesses períodos é que surgirá, entre os pesquisadores, uma preocupação inventiva que não existia na ciência normal; essa preocupação dos pesquisadores se concentrará em criar um novo paradigma.

Antes do surgimento de uma nova teoria, de acordo com Kuhn (1962), sua solução já havia sido antecipada em um período no qual não havia cri- 
se. Como a ausência de crise indica que a teoria vigente é ainda capaz se solucionar os principais problemas, essas antecipações foram ignoradas, sendo apenas consideradas com o surgimento da crise. Como exemplo dessas antecipações, pode-se citar Aristarco, que antecipou a teoria de Copérnico, 18 séculos antes da crise que levou ao desenvolvimento da astronomia heliocêntrica.

\subsection{Revolução Científica}

Outro conceito importante da obra de Kuhn (1962) é o de revolução científica, que é definido pelo autor como a ocorrência de fatos não cumulativos no período em que um paradigma antigo é substituído por um diferente, ou seja, consiste na mudança provocada pela crise da ciência normal. Esse processo é importante porque os cientistas não costumam renunciar ao paradigma, mesmo em momentos de crise; tal renúncia somente acontecerá quando o paradigma for substituído por outro. Assim, os cientistas não abandonam um paradigma pela comparação da teoria com o mundo, mas pela comparação do paradigma antigo com o novo e dos dois com a natureza (KUHN, 1962). De acordo com Kuhn (1962), o início de uma revolução se dá na mente de um cientista. Costumeiramente esse cientista é novo na área e se concentrou nos problemas do paradigma anterior que geraram a crise. Assim, na visão de Kuhn (1970), a emergência de uma consciência mais profunda pode provocar mudanças nas teorias.

Nos períodos de revolução científica, vários paradigmas diferentes competem entre si, e os grupos que os defendem se utilizam do próprio paradigma para a defesa dele, fornecendo, assim, uma amostra de sua prática científica. Cada paradigma, entre os vários que competem entre si, resolve uma parte dos problemas de sua área científica, sendo necessária a definição, por meio de critérios externos, de quais resoluções são mais importantes. Segundo Kuhn (1962), provas não são suficientes para estabelecer qual das teorias é melhor, uma vez que elas discordam, inclusive dos problemas que a outra poderá resolver. Muitas vezes, o paradigma anterior pode se reestruturar para defender-se dos ataques do novo paradigma e o equilíbrio da disputa ser realmente grande. Esse debate entre os paradigmas é revolucionário para a ciência e, ao final, será feita a escolha de um novo paradigma. Para que um novo paradigma consiga se sobrepor a outro, ele necessita de adeptos iniciais que, por meio de suas pesquisas, consigam aperfeiçoá-lo a ponto de res- 
ponder aos problemas da crise. A crise do paradigma anterior, nesse caso, é importante, porque influenciará esses cientistas a adotarem o novo paradigma. Ao final, uma teoria triunfará, não por convencer seus opositores, mas porque a nova geração adotou-a e, ao longo do tempo, acontece a morte de opositores presos a paradigmas anteriores (KUHN, 1962).

Ainda segundo Kuhn (1962), as evoluções da ciência provocam mudanças na visão dos cientistas, mesmo que eles empreguem instrumentos já conhecidos e examinem pontos já estudados. Nesse sentido, mudanças de paradigma levam os cientistas a verem o mundo de outra forma. Isso ocorre porque, de acordo com Kuhn (1962), a visão do cientista depende de treino mediante as teorias.

Kuhn (1962, p. 148) também concebe que "[...] alguma coisa semelhante a um paradigma é um pré-requisito para a própria percepção". O autor fundamenta sua concepção em estudos científicos que mostraram que a visão e a percepção do ser humano não dependem apenas dos olhos, mas também de todo o conhecimento prévio de cada indivíduo e da maneira pela qual está habituado a ver. No entanto, para Kuhn (1962), não é possível afirmar que as observações dos cientistas partilhem dessas características, mas é possível que isso ocorra.

A mudança de um paradigma, como no exemplo de Copérnico, possibilitou uma alteração tão grande na percepção dos cientistas que causou a impressão de que eles passaram a viver em um novo mundo. Uma vez que o novo paradigma possibilitou que, por exemplo, corpos tidos como estrelas passassem a ser considerados planetas, a astronomia "perdeu" várias estrelas e "ganhou" novos planetas.

\subsection{Progresso da Ciência}

O progresso, de acordo com Kuhn (1962), é um requisito reservado à ciência. Isso está relacionado ao próprio termo, uma vez que ciência define áreas que progridem de forma óbvia. No entanto, a definição de ciência é divergente, e tomar apenas o progresso como parâmetro não resolve essas dificuldades de definição.

Em se tratando do progresso da ciência, Kuhn (1962) aponta o isolamento como um fator relevante. $\mathrm{O}$ isolamento consiste no fato de que os cientistas dirigem suas descobertas para a avaliação de outros cientistas da área, diferente de poetas e teólogos que estão mais preocupados com a acei- 
tação do público geral. Dessa forma, após resolver um problema, os cientistas podem passar rapidamente para a solução de outro (KUHN, 1962).

O resultado de uma revolução científica é o progresso, ao menos para o grupo que defendia o paradigma que se sobrepôs. Já a comunidade científica que repudia um paradigma, ao fazê-lo também repudia tudo o que havia sido escrito sobre ele. Esse processo faz com que o cientista tenha uma visão em linha reta da história de sua disciplina, bem como faz parecer que o passado foi orientado para conduzir ao progresso atual (KUHN, 1962).

\subsection{Vantagens da Ciência Normal}

O exemplo da descoberta do oxigênio e outros mencionados por Kuhn (1962) indicam descobertas tardias, pois os fenômenos ocorridos não podiam ser explicados à luz do paradigma vigente e, portanto, os cientistas tardaram a verificar que os resultados obtidos eram anomalias que questionavam o paradigma.

Diante disso e dos aspectos relacionados aos períodos de crise e das revoluções científicas, Kuhn (1962) questiona se os paradigmas devem ser considerados pelos cientistas e responde afirmando que sim, pois são essenciais à ciência. São essenciais, segundo esse mesmo autor, devido ao fato de constituírem a melhor maneira de integração entre as observações e a teoria. Além disso, a confiança no paradigma permite que os cientistas não sejam perturbados por questionamentos irrelevantes.

Kuhn (1962) defende a ciência normal e a adoção de paradigmas, porque, para ele, enquanto o paradigma vigente é capaz de responder aos principais problemas, a ciência avança com rapidez e se aprofunda com a utilização dos instrumentos e métodos desse paradigma. Os próprios paradigmas, para Kuhn (1962), proporcionam o aparecimento de novas descobertas e somente por conhecer com exatidão o paradigma é que o cientista consegue perceber a ocorrência de anomalias.

Kuhn (1962) evidencia cinco vantagens da existência de paradigmas. A primeira é que os paradigmas preparam o estudante para ser um membro da comunidade científica na qual atuará. A segunda está fundamentada em uma diferença entre as pesquisas baseadas ou não em um paradigma. Em consonância com Kuhn (1962), se não houvesse um paradigma comum entre os pesquisadores da área, cada um necessitaria definir seu campo desde os fundamentos. Já as pesquisas com base em um paradigma possibilitam ao 
pesquisador se concentrar em aspectos mais sutis do fenômeno e encontrar resultados mais específicos.

Ao citar o exemplo do paradigma de Franklin, Kuhn (1962) dá destaque à terceira vantagem dos paradigmas, visto que ele possibilitou a unificação e a orientação dos pesquisadores da eletricidade para chegar ao que hoje é considerado verdade nesta área. Assim, o surgimento de um paradigma pode auxiliar as pesquisas de uma área.

A ausência de um paradigma em uma área de pesquisa, para Kuhn (1962), consiste na falta de especificação sobre os aspectos relevantes para aquela área. Como consequência, os pesquisadores podem considerar todos os aspectos envolvidos como relevantes, ampliando demasiadamente sua pesquisa para aprofundar resultados. A resolução desse problema direciona para a quarta vantagem citada por Kuhn (1962).

Quando o paradigma de uma área é instituído, costuma ocorrer um processo de profissionalização ou disciplinarização, por meio do qual são criados jornais especializados na área, fundadas sociedades para os especialistas, passando a haver a busca de um espaço nos currículos de estudo, o que indica a quinta vantagem dos paradigmas citada por Kuhn (1962).

\subsection{A Ciência não é Cumulativa}

Manuais científicos, textos de divulgação e obras filosóficas promovem um processo de invisibilidade às revoluções científicas, uma vez que disfarçam sua existência e significado. Esses manuais costumeiramente apresentam fragmentos da história da área, retratando apenas os "heróis" existentes ao longo dessa história. O fragmento de história retratado engloba apenas as partes que podem ser vistas como contribuição ao paradigma atual, e os cientistas das diferentes épocas são apresentados como se trabalhassem com as mesmas regras, objetivos e problemas que o paradigma vigente tornou científico. Esse processo acarreta uma visão cumulativa da ciência que, para Kuhn (1962), é enganosa, não considerando as revoluções ocorridas (KUHN, 1962).

Esse processo que negligencia a ocorrência das revoluções é grave, porque profissionais e leigos têm como principal fonte de informações os manuais os quais, visando aproximar os estudantes do paradigma atual, costumam isolar e sintetizar, o máximo possível, as experiências, os conceitos, as leis e as teorias da ciência normal. As distorções sobre a história da ciência 
apresentadas nos manuais tornam as revoluções científicas invisíveis, e o material histórico que permanece provoca uma visão errônea. Conforme Kuhn (1962), as revoluções não teriam sentido algum, uma vez que o conhecimento científico teria evoluído ao ponto atual por meio da acumulação do conhecimento.

\subsection{Implicações dos Pressupostos de Kuhn para a Administração}

Damke, Silva e Walter (2010) destacam que as concepções de Kuhn foram interpretadas por muitos pesquisadores como critérios de cientificidade. Assim, para esse grupo de pesquisadores, possuir um paradigma tornou-se um pré-requisito de maturidade para qualquer ciência, o que gera discussões a respeito da cientificidade da administração.

As ciências sociais e, consequentemente, a administração poderiam ser consideradas como imatura ou pré-paradigmáticas, visto que, diante de seu recente surgimento, ainda não puderam consolidar seu paradigma ${ }^{3}$. Para Kuhn (1962), as ciências imaturas ou pré-paradigmáticas não possuem um conjunto hegemônico de ideias fundamentais, ou seja, uma concepção geral com a qual a maioria dos pesquisadores esteja de acordo e as empregue no desenvolvimento de seus trabalhos. Assim, é comum a disputa entre grupos de cientistas que querem impor suas ideias aos demais membros da área.

Nesse sentido, na administração, assim como em outras ciências sociais, podem ser encontrados múltiplos paradigmas que convivem entre si. Isso pode estar relacionado aos fenômenos estudados por essas ciências que são mais complexos e variáveis, assim como pelo surgimento mais recente, o que demandaria um tempo de amadurecimento.

A revisão de literatura apresentada nesta seção, sobre a obra A estrutura das revoluções científicas, de Kuhn (1962), teve por objetivo demonstrar os principais apontamentos e conceitos que podem contribuir com a área de administração.

\footnotetext{
${ }_{3}^{3}$ Há pesquisadores que defendem que a administração possui alguns paradigmas ou que os critérios de cientificidade das ciências naturais (como o caso de Kuhn) não deveriam ser empregados para análise das ciências sociais, mas estes aspectos não serão aprofundados neste artigo. Para esta discussão ver Santos (2003).
} 


\section{Método da Pesquisa}

Para a realização deste estudo, fez-se uma pesquisa bibliográfica e outra bibliométrica. Segundo Jung (2004, p. 160), o estudo bibliográfico objetiva "[...] conhecer as diversas formas de contribuições científicas existentes que foram realizadas sobre determinado assunto ou fenômeno". Para Cruz e Ribeiro (2003, p. 12), este tipo de estudo "[...] pode visar a um elemento dos trabalhos realizados anteriormente sobre o mesmo tema estudado no momento, pode identificar e selecionar os métodos e técnicas a serem utilizados, além de fornecer subsídios [...]" para a pesquisa. Já a pesquisa bibliométrica aplica métodos quantitativos e matemáticos à produção, divulgação e utilização de informações registradas (MACIAS-CHAPULA, 1998).

Com base nas orientações metodológicas de Jung (2004), Cruz e Ribeiro (2003) e Macias-Chapula (1998), fez-se a revisão, nos artigos publicados nos anais do EnANPAD no período de 1997 a 2007, de trabalhos sobre administração que citaram a obra A estrutura das revoluções científicas, de Kuhn, e se procedeu à análise desses trabalhos, empregando, para isso, o método qualitativo e o quantitativo. Ressalta-se que a escolha do referido período de publicação se deu em virtude de os anais do EnANPAD serem disponibilizados em CD-ROMs a partir da edição de 1997.

A opção por realizar a pesquisa nos artigos publicados nos anais do EnANPAD deu-se pelo fato de esse encontro, segundo Bignetti e Paiva (2001), reunir anualmente muitos dos principais pesquisadores brasileiros de administração, principalmente os vinculados a programas de pós-graduação. A opção também se deu pelo fato de o EnANPAD representar, conforme Vergara e Pinto (2000), um espaço que fornece a oportunidade para autores de diferentes instituições divulgarem suas pesquisas e ser considerado um dos mais representativos eventos da área de administração.

A obtenção dos artigos a serem revisados se deu por buscas eletrônicas nos CD-ROMs do evento por meio das palavras-chave: Thomas Kuhn, Kuhn e Kuhniano. Dos artigos encontrados, excluíram-se da amostra os que se referiam a outras obras de Kuhn que não $A$ estrutura das revoluções científicas. Também se realizaram buscas em artigos que citavam a palavra paradigma no sentido conferido por Kuhn e a palavra paradigma não relacionada ao sentido desenvolvido pelo autor. Assim, foram localizados 66 artigos.

Para análise dos dados, comparou-se o número total de artigos publicados em cada edição do EnANPAD e o número total das 11 edições com o 
número de artigos que citavam Kuhn (1962). Também se verificou a frequência de questões relativas ao número de autores dos artigos revisados, aos autores que mais apareciam nesses artigos, bem como a instituição à qual se vinculavam, as áreas temáticas do EnANPAD nas quais se encontram publicados os estudos e os enfoques dados nos estudos à obra $e$ concepções de Kuhn (1962).

Ressalta-se que, para a análise das áreas temáticas nas quais foram publicados os artigos da amostra, inicialmente se realizou uma análise de conteúdo em relação aos nomes e especificações de cada área, uma vez que, durante as edições do EnANPAD, o nome dado às áreas se altera. Esse procedimento visou garantir que os artigos fossem agrupados em suas respectivas áreas de estudo, independente de alterações na nomenclatura dessas áreas.

Para identificação de referências à obra de Kuhn (1962), ao próprio autor ou às suas concepções e conceitos, que indicassem o enfoque principal do autor presente nos estudos, utilizou-se a análise de conteúdo. Para Hair Jr. et al. (2005), a análise de conteúdo consiste na observação e na análise da frequência de temas e palavras presentes em textos escritos. Por sua vez, para Moraes (1999), por meio da análise de conteúdo técnica, podem-se categorizar as frases e descrever a estrutura lógica das expressões.

Ressalta-se que um dos 66 estudos analisados recebeu a atribuição de dois enfoques, por dar ênfase a dois conceitos de Kuhn (1962), o que fez com que houvesse um total de 67 enfoques. Uma vez realizada a análise que identificou os enfoques, fez-se o agrupamento dos mesmos, conforme seu conteúdo, para análise da frequência de cada um. A análise dos enfoques dados aos conceitos de Kuhn (1962), nos artigos pesquisados, e dos próprios conceitos do autor permitiu verificar como esses conceitos estão e como podem contribuir com a área de Administração.

Na próxima seção, serão apresentados, em tabelas e gráficos, os resultados obtidos e será realizada a análise e a interpretação desses resultados.

\section{Análise e Interpretação dos Dados}

Nesta seção, é realizada a apresentação, a análise e a interpretação dos resultados obtidos no que concerne aos estudos que citam Kuhn (1962), à quantidade de autores por artigo, aos autores que mais citam Kuhn (1962), 
às áreas com maior concentração de estudos da amostra e aos enfoques observados a respeito de Kuhn (1962) nos estudos revisados.

Na Tabela 1, apresenta-se o total de artigos publicados no EnANPAD e os artigos que citam Kuhn (1962) encontrados por meio das buscas nos anais do evento.

Tabela 1: Artigos do EnANPAD encontrados por meio das buscas nos anais do evento

\begin{tabular}{|c|c|c|c|c|c|c|c|c|c|c|c|c|}
\hline \multirow[b]{2}{*}{ Artigos } & \multicolumn{11}{|c|}{ Número de artigos por edição do EnANPAD } & \multirow[b]{2}{*}{ Total } \\
\hline & ลิ & $\stackrel{\infty}{2}$ & बे & రి & ర్రి & ণิ & ஜి & ర్ & ำ & ปั & ণิ & \\
\hline Artigos do EnANPAD & 241 & 250 & 265 & 368 & 426 & 554 & 629 & 799 & 791 & 836 & 973 & 6.132 \\
\hline $\begin{array}{l}\text { Artigos do EnANPAD } \\
\text { que citam Kuhn (1962) }\end{array}$ & 4 & 4 & 4 & 5 & 5 & 4 & 5 & 7 & 8 & 9 & 11 & 66 \\
\hline
\end{tabular}

Fonte: Dados da pesquisa

O total de artigos publicados no EnANPAD, no período de 1997 a 2007, foi de 6.132, e o total de artigos que mencionam Kuhn (1962) foi de 66. No que tange à distribuição temporal, observa-se que, a partir de 2004, houve um acréscimo gradativo no número de artigos publicados que citam Kuhn, atingindo 11 artigos em 2007.

Na Tabela 2, expõe-se o total de autores por artigo, classificados por ano.

Tabela 2: Número de autores por artigo e as edições nas quais os artigos foram publicados

\begin{tabular}{|c|c|c|c|c|c|c|c|c|c|c|c|c|}
\hline \multirow[b]{2}{*}{$\begin{array}{c}\text { Número de autores } \\
\text { por artigo }\end{array}$} & \multicolumn{11}{|c|}{ Número de artigos por edição do EnANPAD } & \multirow[b]{2}{*}{ Total } \\
\hline & ลิ & $\stackrel{\infty}{2}$ & बे & $\begin{array}{l}\text { ᄋ } \\
\text { ণ }\end{array}$ & ్ㅗㅇ & 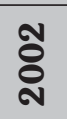 & ஜి & ర్ & $\begin{array}{l}\text { L } \\
\text { 오 }\end{array}$ & $\begin{array}{l}\text { ீ: } \\
\text { రి }\end{array}$ & કิષิ & \\
\hline 1 & 3 & 1 & 2 & 4 & 2 & 3 & 3 & 1 & 2 & 3 & 3 & 27 \\
\hline 2 & 1 & 1 & 2 & 1 & 2 & 1 & 2 & 4 & 3 & 5 & 7 & 29 \\
\hline 3 & - & 2 & - & - & 1 & - & - & 1 & 3 & 1 & - & 8 \\
\hline 4 & - & - & - & - & - & - & - & - & - & - & 1 & 1 \\
\hline 5 & - & - & - & - & - & - & - & 1 & - & - & - & 1 \\
\hline
\end{tabular}

Fonte: Dados da pesquisa 
Verifica-se, na Tabela 2, que os artigos que fazem menção a Kuhn são, em sua maioria, em um total de 29 artigos, escritos por dois autores; em seguida, há 27 artigos escritos por apenas um autor. Já com números expressivamente menores, encontram-se oito artigos escritos por três autores; um escrito por quatro autores; e um, por cinco autores.

A Tabela 3 apresenta os autores que mais publicaram artigos referenciando Kuhn $e$ as instituições às quais esses pesquisadores estavam vinculados no momento da publicação, de acordo com as respectivas edições.

Tabela 3: Autores que mais citaram Kuhn, a instituição à qual estão vinculados e as edições nas quais os artigos foram publicados

\begin{tabular}{|c|c|c|c|c|c|c|c|c|c|c|c|c|c|}
\hline \multirow{2}{*}{ Autores } & \multirow{2}{*}{ 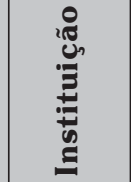 } & \multicolumn{11}{|c|}{ Número de artigos por edição do EnANPAD } & \multirow[b]{2}{*}{$\begin{array}{l}\text { To- } \\
\text { tal }\end{array}$} \\
\hline & & बे & $\begin{array}{l}\infty \\
\stackrel{\alpha}{\sigma}\end{array}$ & बे & §ి & ర్రి & ญి & ஜ̊ & ঠి & 용 & ஓ̊ & 옹 & \\
\hline \multirow{2}{*}{ FARIA, Alexandre } & PUCPR & - & - & - & - & 2 & 1 & - & 1 & - & - & - & 5 \\
\hline & FGV & - & - & - & - & - & - & - & - & 1 & - & - & \\
\hline MATTOS, Pedro L. C. L. de & UFPE & - & - & - & 1 & 1 & - & - & - & 1 & 1 & - & 4 \\
\hline GIGLIO, Ernesto M. & UNIP & - & - & - & - & - & - & - & - & 1 & 1 & - & 2 \\
\hline GONÇALVES, Sandro A. & UFPR & 1 & - & 1 & - & - & - & - & - & - & - & - & 2 \\
\hline KWASNICKA, Eunice L. & UNIP & - & - & - & - & - & - & - & - & 1 & 1 & - & 2 \\
\hline MOREIRA, Luiz A. A, & UECE & - & - & - & - & - & - & 1 & - & 1 & - & - & 2 \\
\hline MACHADO-DA-SILVA, Clóvis L. & UFPR & - & - & 1 & - & - & - & - & - & - & - & 1 & 2 \\
\hline TONELLI, Dany F. & UFLA & - & - & - & - & - & - & - & - & - & 1 & 1 & 2 \\
\hline
\end{tabular}

Fonte: Dados da pesquisa

Por meio da Tabela 3 verifica-se que os autores que mais citaram Kuhn foram: Alexandre Faria vinculado, inicialmente, à Pontifícia Universidade Católica (PUCPR) e, posteriormente, à Fundação Getúlio Vargas (FGV), com cinco artigos que fazem menção a Kuhn, seguido de, Pedro Lincoln C. L. de Mattos, da Universidade Federal de Pernambuco (UFPE), com quatro artigos publicados. Com dois artigos publicados, constam os autores Ernesto Michelângelo Giglio e Eunice Lacava Kwasnicka, da Universidade Paulista (UNIP); Sandro A. Gonçalves, da Universidade Federal do Paraná (UFPR); Luiz Alcione Albandes Moreira, da Universidade Estadual do Ceará (UECE); Clóvis L. Machado-da-Silva, da Universidade Federal do Paraná (UFPR); e 
Dany Flávio Tonelli, da Universidade Federal de Lavras (UFLA). Em complemento, ressalta-se que um número expressivamente grande de autores, totalizando 98, apresentou um artigo citando Kuhn.

$\mathrm{Na}$ Tabela 4, os artigos que citam Kuhn são classificados de acordo com as áreas temáticas nas quais foram publicados.

Tabela 4: Artigos do EnANPAD por áreas

\begin{tabular}{|c|c|c|c|c|c|c|c|c|c|c|c|c|}
\hline \multirow[b]{2}{*}{$\begin{array}{c}\text { Áreas Temáticas do } \\
\text { EnANPAD }\end{array}$} & \multicolumn{11}{|c|}{ Número de artigos por edição do EnANPAD } & \multirow[b]{2}{*}{ Total } \\
\hline & ลิ & ळ̊ & ूे & $\begin{array}{l}\text { ̊̊ } \\
\text { ஜํ }\end{array}$ & ฮั่ & ช్ & ๕ั & ర్ & ๕ั่ & ஜ & ฮิ & \\
\hline Ensino e pesquisa & - & - & - & - & 3 & 3 & 2 & 1 & 4 & 3 & 5 & 21 \\
\hline $\begin{array}{l}\text { Estudos } \\
\text { organizacionais }\end{array}$ & 2 & 3 & 3 & 3 & 1 & 0 & 2 & 1 & 0 & 0 & 3 & 18 \\
\hline $\begin{array}{l}\text { Administração pública } \\
\text { e gestão social }\end{array}$ & 0 & 1 & 1 & 1 & 1 & 0 & 0 & 2 & 0 & 1 & 0 & 7 \\
\hline Marketing & 1 & 0 & 0 & 0 & 0 & 0 & 0 & 1 & 2 & 2 & 0 & 6 \\
\hline Estratégia & 1 & 0 & 0 & 0 & 0 & 1 & 0 & 0 & 1 & 1 & 1 & 5 \\
\hline $\begin{array}{l}\text { Administração da } \\
\text { informação }\end{array}$ & 0 & 0 & 0 & 0 & 0 & 0 & 0 & 1 & 0 & 1 & 1 & 3 \\
\hline $\begin{array}{l}\text { Ciência, tecnologia e } \\
\text { inovação }\end{array}$ & 0 & 0 & 0 & 1 & 0 & 0 & 0 & 0 & 0 & 1 & 1 & 3 \\
\hline Agronegócios & - & - & - & - & - & - & 1 & 1 & - & - & - & 2 \\
\hline $\begin{array}{l}\text { Gestão de pessoas e } \\
\text { relações de trabalho }\end{array}$ & 0 & 0 & 0 & 0 & 0 & 0 & 0 & 0 & 1 & 0 & 0 & 1 \\
\hline
\end{tabular}

Fonte: Dados da pesquisa

A Tabela 4 permite perceber que as áreas do EnANPAD que possuem mais artigos citando Kuhn são a de ensino e pesquisa, com 21 artigos, e a de estudos organizacionais, com 18 artigos. As demais áreas com artigos que citavam Kuhn são: administração pública e gestão social, com sete artigos; marketing, com seis artigos; estratégia, com cinco artigos; administração da informação, com três artigos; ciência, tecnologia e inovação, também com três artigos; agronegócios, com dois artigos; e gestão de pessoas e relações de trabalho, com um artigo. Destaca-se que a área de ensino e pesquisa não esteve presente nas edições de 1997 a 2000 e que a área de agronegócios fez parte apenas das edições de 2003 e 2004. 
Na Figura 1 são apresentados os enfoques de Kuhn de acordo com os artigos revisados.

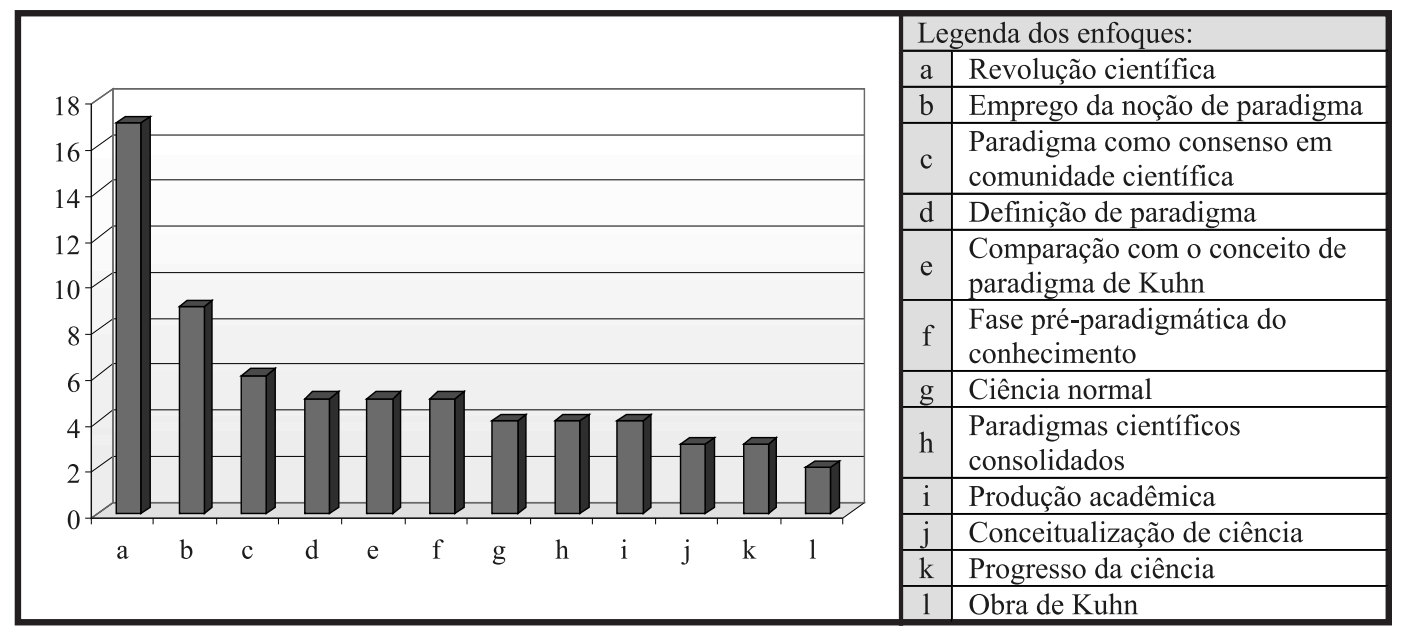

Figura 1: Enfoques de Kuhn nos artigos revisados

Fonte: Dados da pesquisa

É perceptível, na Figura 1, que o enfoque mais presente nos artigos revisados concentra-se no tema revolução científica, totalizando 17 ocorrências. Kuhn (1962) define revolução científica como fatos não cumulativos em que um paradigma antigo é substituído por outro diferente. Percebe-se, assim, que a ocorrência de uma revolução científica está associada, na teoria de Kuhn (1962), à quebra ou à emergência de um paradigma. Nesse sentido, de acordo com Kuhn (1962), uma descoberta que altera o empreendimento científico é chamada de anomalia, pois viola as expectativas do paradigma que regiam a ciência normal até então. Assim, o paradigma precisa ser alterado para que a anomalia se transforme no esperado e se torne científico, ou seja, se transforme em um novo paradigma (KUHN, 1962).

Assim, se agruparam sob esse enfoque indicações que apresentam exemplos, análises e discutem a necessidade de mudança ou emergência de paradigmas; que destacam a necessidade de rompimento com o paradigma vigente para gerar inovação; que associam mudança organizacional e quebra de paradigmas; que propõem que mudanças na sociedade ocorrem por meio da quebra de paradigmas; e que criticam estudos dentro de um paradigma, defendendo a realização de pesquisas com interdisciplinaridade e em múltiplos níveis. 
Essa concepção de revolução científica pode contribuir com o campo de administração para explicar os motivos pelos quais, em determinado período de tempo, uma teoria domina uma área e, depois, outra teoria se sobrepõe a essa. Como exemplo, pode-se utilizar a área de estratégia, na qual, até o final dos anos de 1980, prevaleciam os estudos embasados na Teoria das Cinco Forças, de Porter, e hoje há predominância dos estudos sob a perspectiva da visão baseada em recursos (VBR). (TONDOLO; BITENCOURT, 2005).

Observou-se, nos estudos revisados, que o conceito de revolução científica também pode auxiliar na explicação de processos, como o de inovação e o de realização de estudos que utilizem a interdisciplinaridade e a pesquisa em multiníveis, vinculando a necessidade de quebra de um paradigma para sua ocorrência, bem como os processos de mudança na sociedade e a mudança organizacional, que ocorreriam a partir da quebra de um paradigma.

O conceito de paradigma, segundo enfoque mais presente nos estudos revisados, com nove apontamentos, foi empregado para a análise de estudos organizacionais, das linhas de estudo em comportamento do consumidor; para uma reflexão sobre a ética nas organizações; para o debate sobre teoria organizacional; para explicar concepções que se tornaram paradigmas; para verificar os impactos da visão do mundo capitalista no século XX e das forças internas do campo de estudos organizacionais; para justificar a realização de estudo sobre paradigmas filosóficos e operacionais; para explicar o taylorismo como um paradigma organizacional do Brasil e para demonstrar sua aplicação para a teoria da ciência, para a teoria do conhecimento e para a área de administração no ocidente.

O terceiro enfoque mais observado, com seis ocorrências, também se relaciona a paradigmas, especificamente ao paradigma como consenso em uma comunidade científica. Quando um paradigma é adotado, sob a ótica de Kuhn (1962), todas as teorias pré-existentes na área desaparecem, ocorre a adesão de um grande grupo de partidários e os pesquisadores que não concordam com o paradigma são excluídos e têm seus trabalhos ignorados.

As ideias agrupadas sob esse enfoque concentram-se no consenso entre os pesquisadores, no consenso social, na tentativa de consenso em uma comunidade de pesquisadores, na importância de um paradigma compartilhado, no consenso científico em torno da refutação do paradigma corrente ou da inconsistência de novos paradigmas e na adoção de um paradigma para a emancipação de uma disciplina. 
Tomando emprestado um exemplo da área de comportamento do consumidor, pode-se dizer que a ideia de consenso sobre um paradigma ajuda a explicar o "foco em marketing" (BLACKWELL; MINIARD; ENGEL, 2005), adotado hoje nesta área em detrimento dos focos na produção e nas vendas existentes anteriormente.

Já a definição do termo paradigma, quarto enfoque mais observado, com cinco apontamentos, refere-se ao próprio conceito de paradigma de Kuhn, do paradigma como crença $e$ valores $e$ da incomensurabilidade $e$ relativismo entre diferentes paradigmas.

O paradigma, para Kuhn (1962), consiste em uma realização científica que se torna modelo para as demais pesquisas daquela área, definindo problemas e métodos que podem ser utilizados por todos. Assim, destaca-se que o conceito de paradigma pode ser utilizado em administração para compreender o predomínio das pesquisas de cunho funcionalista ou positivista (MACHADO-DA-SILVA; CUNHA; AMBONI, 1990; MARTINS, 1996). Além disso, a noção de paradigma é empregada para explicar aspectos variados nos estudos revisados, como já apontado, sobre o emprego do conceito de paradigma de Kuhn (1962).

Também com cinco ocorrências, percebe-se o enfoque comparação entre o conceito de paradigma de Kuhn (1962) com outros conceitos de paradigma. Os paradigmas relacionados ou comparados ao paradigma de Kuhn foram: paradigma tecnológico, paradigma tecnoeconômico e paradigma na concepção de Burrell e Morgan. Outra analogia relaciona-se ao fato de que uma experiência dada pode ser entendida de múltiplas formas na analogia ao paradigma de Kuhn. Segundo Santos e Pinto (2007), Kuhn foi o primeiro autor a utilizar o termo paradigma. Dessa forma, percebe-se que a teoria de Kuhn apresenta-se útil na administração para a comparação com outras acepções do termo paradigma e na definição dessa área, como ocorre em alguns dos estudos revisados.

Ainda com cinco apontamentos, tem-se o enfoque dado ao conceito de fase pré-paradigmática do conhecimento. Os conhecimentos em fase pré-paradigmática citados pelos estudos revisados foram sobre redes e empreendedorismo. Além disso, tem-se a proposição de que, antes de gerar aplicações úteis e significativas, deve-se alcançar um patamar mínimo de maturação e desenvolvimento de um conhecimento.

Os períodos pré-paradigmáticos, de acordo com Kuhn (1962), pedem a refutação do conhecimento anterior para o estabelecimento de um novo 
conhecimento, ou seja, consistem no período de transição entre o antigo e o novo paradigma ou no período preparatório para consolidação de um paradigma. Nesse sentido, a concepção de períodos pré-paradigmáticos pode auxiliar na explicação dos períodos que preconizam a consolidação de paradigmas em administração. Exemplos de períodos pré-paradigmáticos talvez sejam os indicados pelos próprios estudos revisados: a área de empreendedorismo (BOAVA; MACEDO, 2006; RODRIGUES, 2007) e do conhecimento sobre redes (GIGLIO; KWASNICKA, 2005; GIGLIO; KWASNICKA; SANTOS, 2006).

Na quinta colocação, há três enfoques, com quatro ocorrências: ciência normal, paradigmas científicos consolidados e produção acadêmica. Sobre a ciência normal, foi citada a importância da concepção kuhniana de ciência normal para a teoria da ciência, para a teoria do conhecimento e para a área de administração no ocidente. Também foi citado que métodos preçossombra, que são os que objetivam valorar monetariamente todos os custos e benefícios, tangíveis e intangíveis, de um projeto, fazem parte de uma lógica comum da ciência normal; que a gestão de pessoas por competências deve procurar uma abordagem contrária à ciência normal; e que a ciência normal proporciona informações para o administrador.

Kuhn (1962) aponta que a maioria dos trabalhos da ciência normal objetiva a reformulação de paradigmas, procurando produzir mudanças que clarifiquem sua definição, tornando-a mais coerente e uniforme. Assim, segundo Kuhn (1962), o objetivo da ciência normal é aumentar a precisão e o alcance do paradigma, e não produzir novidades. Kuhn (1962) aponta, ainda, que os conceitos de ciência normal e de paradigma estão interligados, uma vez que pesquisadores que atuam dentro de um mesmo paradigma compartilham regras e padrões comuns para suas pesquisas, sendo isso tido como um requisito para a ciência normal.

Partindo da concepção de ciência normal de Kuhn (1962), como a de estudos que procuram melhorar e comprovar um paradigma sem contrariálo, percebe-se que essa concepção auxilia na compreensão da ocorrência de alguns estudos na área de administração que, antes da apresentação dos resultados, dão indícios dos resultados que desejam encontrar. Isso ocorre porque os pesquisadores, impregnados de um paradigma, realizam toda a revisão de literatura e, às vezes, até dos objetivos, com base em uma teoria ou método, apontando que desejam que os resultados de sua pesquisa corroborem os apontamentos de tal teoria ou método. Outro exemplo desse tipo de estudo é o que se propõe a aperfeiçoar uma teoria ou método. 
O enfoque paradigmas científicos consolidados traz apontamentos sobre o fato de que cada época possui uma visão do mundo e estabelece um paradigma por meio do qual interpreta e constrói a realidade; que paradigmas estabelecidos e enraizados forçam o pesquisador a uma percepção quase pré-determinada e estreita da realidade; e que, em cursos de administração, usam-se manuais que pressupõem a existência de paradigmas científicos consolidados e confiáveis. Percebe-se que essa noção de paradigma consolidado se relaciona aos conceitos de ciência normal de Kuhn (1962), uma vez que a consolidação de um paradigma consiste no pré-requisito para a ciência normal.

No que tange ao enfoque produção acadêmica, observou-se a indicação de que estudos mascaram a influência do pesquisador e de suas teorias; de que não se sabe até que ponto se tem consciência clara do paradigma que informa a escolha epistemológica nos estudos; de que, quando os estudos pós-modernos passaram a infiltrar os estudos organizacionais, a discussão sobre Kuhn passou a ser obrigatória; e de que a incomensurabilidade dos discursos científicos, sustentada por Kuhn, construídos sob paradigmas diferentes, toma novo impulso.

Com três ocorrências, obtiveram-se os enfoques conceitualização de ciência e progresso da ciência, em sexta colocação. A conceitualização de ciência apontou o conceito de ciência para Kuhn (1962) e que, após as críticas de Popper, Kuhn e Lakatos, a ciência não se constitui em uma verdade única e que a forma de proceder cientificamente depende do conceito que se tem de ciência, ou seja, do paradigma adotado. Como já destacado, para Kuhn (1962), a ciência consiste na adoção de um paradigma dentro da ciência normal, alternada por períodos de crise em que ocorre a revolução científica e a quebra do paradigma vigente. Esses conceitos de ciência normal e de revolução científica podem ser úteis à área de administração, conforme observado na descrição dos enfoques anteriores.

O progresso da ciência, segundo Kuhn (1962), ocorre por meio das revoluções científicas, ou seja, por meio da quebra de paradigmas. Dessa forma, agruparam-se sob este enfoque as indicações de que o progresso da ciência acontece por meio da quebra de paradigmas; de que a quebra de paradigmas é importante para o progresso da ciência; e de que a epistemologia antropofágica apoia-se em Kuhn e despreza a ideia de que uma área deve apresentar um progresso marcante para ser considerada científica. Isso porque Kuhn (1962) defende a ciência normal na qual não ocorre grande progresso científico. 
O último enfoque observado em ordem de ocorrências é o que faz referência à obra A estrutura das revoluções científicas, de Kuhn (1962), com dois apontamentos: a obra produziu um abalo na ciência, iniciando uma polêmica sobre a natureza da ciência, bem como foi escrita por Kuhn após tentativas de unificação ontológica e epistemológica. A citação de A estrutura das revoluções científicas nos estudos revisados corrobora a ideia de que essa obra de Kuhn contribui com os estudos em administração no Brasil.

$\mathrm{Na}$ área de estudos organizacionais, houve cinco citações de Kuhn relacionando-o ao enfoque de revolução científica; quatro para o emprego de paradigma; três para a definição de paradigma; duas para conceitualização de ciência; e uma para os enfoques relacionados à obra, a paradigma como consenso em uma comunidade científica, a paradigmas científicos consolidados e à comparação do paradigma de Kuhn a outro conceito de paradigma.

Os artigos localizados por meio das buscas passaram por um processo de revisão dos conteúdos e foram classificados em dois grupos, descritos na Tabela 5 .

Tabela 5: Artigos do EnANPAD que citam paradigma e artigos que não citam

\begin{tabular}{|c|c|c|c|c|c|c|c|c|c|c|c|c|}
\hline \multirow[b]{2}{*}{$\begin{array}{l}\text { Sentido do } \\
\text { Paradigma }\end{array}$} & \multicolumn{11}{|c|}{ Número de artigos por edição do EnANPAD } & \multirow[b]{2}{*}{ Tota } \\
\hline & ลू & $\stackrel{\infty}{\Omega}$ & รั & §ి & ฮి & ญి & ๕ి & ঠి & ำ & ๕̊ & ํํํ & \\
\hline $\begin{array}{l}\text { Artigos que citam } \\
\text { paradigma no sentido } \\
\text { desenvolvido por Kuhn }\end{array}$ & 4 & 4 & 4 & 5 & 3 & 4 & 4 & 4 & 6 & 10 & 10 & 58 \\
\hline $\begin{array}{l}\text { Artigos que citam } \\
\text { paradigma, porém não } \\
\text { no sentido desenvolvi- } \\
\text { do por Kuhn }\end{array}$ & 1 & - & - & - & 1 & - & - & - & - & - & - & 2 \\
\hline $\begin{array}{l}\text { Artigos que não citam } \\
\text { paradigma }\end{array}$ & - & - & - & - & 1 & - & 1 & 2 & 2 & - & 1 & 7 \\
\hline
\end{tabular}

Fonte: Dados da pesquisa

Conforme a Tabela 5, os artigos que citam paradigma no sentido desenvolvido por Kuhn somam 58, o que representa um crescimento no número de citações a partir de 2006. Os artigos que não o citam totalizam dois, e os artigos que não citam paradigma somam sete. Destaca-se que a soma das três categorias é 67, porque um dos artigos publicados em 1997 emprega o 
conceito de paradigma tanto no sentido de Kuhn quanto em um sentido distinto e que a maioria dos artigos analisados - $86,57 \%$ - cita paradigma no sentido de Kuhn.

\section{Considerações Finais}

Neste estudo, que teve como um dos objetivos analisar como os conceitos desenvolvidos por Kuhn (1962) têm contribuído e como podem contribuir com a área de administração, se fez a revisão de 66 artigos publicados nos anais do EnANPAD, no período de 1997 a 2007, que citavam a obra A estrutura das revoluções científicas de Kuhn.

Verificou-se a predominância, em 29 artigos, do número de dois autores por artigo, seguida de um autor em 27 artigos, o que demonstra que os estudos revisados apresentam uma tendência à realização de pesquisas com número reduzido de participantes, quer seja individualmente ou em grupo. Também se constatou que, da amostra pesquisada, os autores que mais citaram Kuhn (1962) foram Alexandre Faria, vinculado inicialmente à PUCPR e, posteriormente, à FGV, com cinco artigos, e Pedro L. C. L. de Mattos, da EFPE, com quatro artigos. Sobre as áreas do EnANPAD, a constatação foi de que a maior concentração de estudos que citaram Kuhn (1962) está nas áreas de ensino e pesquisa, com 21 artigos, e a de estudos organizacionais, com 18 artigos. Esse resultado indica que os conceitos de Kuhn (1962) têm sido utilizados e estão contribuindo em maior grau com essas áreas.

Quanto aos enfoques nos conceitos de Kuhn (1962), averiguou-se que os estudos citaram: revolução científica (dezessete ocorrências); emprego da noção de paradigma (nove ocorrências); paradigma como consenso em comunidade científica (seis ocorrências); definição de paradigma, comparação com o conceito de paradigma de Kuhn e fase pré-paradigmática do conhecimento (cinco ocorrências cada); ciência normal, paradigmas científicos consolidados e produção acadêmica (quatro ocorrências cada); conceitualização de ciência e progresso da ciência (três ocorrências cada); e obra de Kuhn (duas ocorrências).

No que concerne ao resultado obtido quanto aos enfoques relacionados ao conceito de paradigma, obtiveram-se 29 ocorrências referentes ao conceito de paradigma de Kuhn (1962). Da mesma forma, agregados os enfoques de revolução científica e de progresso da ciência que, como já vis- 
to, ocorre por meio da revolução científica, obtiveram-se 20 ocorrências referentes ao conceito de revolução científica de Kuhn (1962). Nesse mesmo sentido, somados os enfoques sobre ciência normal e conceitualização de ciência, obtiveram-se sete ocorrências com relação ao conceito de ciência de Kuhn. Também se ressalta que o conceito de fase pré-paradigmática de Kuhn (1962) foi utilizado em cinco diferentes estudos revisados.

Empregando os mesmos critérios utilizados com o número total de artigos, se obtiveram, quanto aos estudos da área de estudos organizacionais, dez referências ao conceito de paradigma; cinco ao conceito de revolução científica; e duas ao conceito de ciência de Kuhn.

Dessa forma, percebeu-se que os três conceitos principais tratados por Kuhn (1962) estão presentes nos estudos revisados, bem como o conceito de fase pré-paradigmática. Conclui-se, assim, que a obra de Kuhn (1962) tem contribuído com a área de administração, principalmente no que concerne aos conceitos de paradigma e revolução científica, e, apesar de em menor grau, aos conceitos de ciência normal e fase pré-paradigmática.

A predominância na utilização do conceito de revolução científica sobre o de ciência normal nos estudos revisados e a emergência do conceito fase pré-paradigmática entre os mais citados podem estar relacionadas com os apontamentos de autores como Bertero, Caldas e Wood Jr. (1998) e Thompson (1956) de que a própria administração, enquanto grande área, estaria em estado embrionário ou em desenvolvimento, visto ser uma ciência jovem e, portanto, ainda não estaria sendo observada a ocorrência de uma ciência normal.

A grande ocorrência do conceito de paradigma de Kuhn (1962) nos estudos revisados ratifica o apontado por Santos e Pinto (2007) de que Kuhn foi o primeiro a utilizar o termo paradigma, demonstrando, assim, a importância de citar o autor ao utilizar esse conceito.

Chega-se à conclusão de que os conceitos da obra de Kuhn (1962), voltada, inicialmente, para as ciências exatas, podem contribuir com o entendimento de características da área de administração. É possível entender, por exemplo, por meio do conceito de revolução científica, os motivos pelos quais, em determinado período de tempo, uma teoria domina uma área, e, depois, outra teoria se sobrepõe a essa; por meio do conceito de paradigma, por que uma realização científica se torna modelo para as demais pesquisas daquela área; por meio do conceito de ciência normal, por que muitas pesquisas são realizadas em acordo com uma perspectiva já existente; e, por 
meio do conceito de fase pré-paradigmática, já que a administração não possui uma teoria geral consolidada.

Quanto ao objetivo que se tinha de verificar se os estudos que citam o conceito de paradigma o faziam no mesmo sentido atribuído por Kuhn (1962), se conclui que os estudos revisados utilizam o termo paradigma em acordo com Kuhn (1962), comprovando, mais uma vez, a contribuição desse conceito e da obra de Kuhn (1962) para a área de administração.

Quanto às limitações desta pesquisa, cita-se a amostra, visto que ela se restringiu aos dados de um dos eventos nacionais da área de administração. Nesse sentido, sugere-se, para futuros estudos, pesquisar outros eventos e periódicos a fim de ampliar os resultados obtidos, bem como revisar estudos internacionais para que os resultados possibilitem verificar se existem diferenças quanto à contribuição dos conceitos de Kuhn (1962) em diferentes países.

\section{The contribution of Thomas Kuhn for the Scientific Production in Management}

\section{Abstract}

This study aims to examine how the concepts developed by Kuhn in The structure of scientific revolutions work have and can contribute to studies of the administration area. Another objective is to verify if the administration area uses the term paradigm as the meaning assigned by Kuhn. A literature and bibliometric search was performed in the studies of the EnANPAD, from 1997 to 2007. It was found, in the 66 studies with quotes from Kuhn (1962), that the areas of EnANPAD that have more articles citing the author are from education and research and organizational studies. It was found that, the most revised studies employs the term paradigm as the meaning assigned by Kuhn (1962) and that the most cited concepts are scientific revolution, paradigm, pre-paradigmatic stage and normal sciences. It was identified as such concepts are contributing to the administration, especially as regards to the understanding of characteristics of this study area.

Key words: Thomas Kuhn. Structure of Scientific Revolutions. Paradigm. 


\section{Referências}

BERTERO, C. O.; CALDAS, M. P; WOOD JR., T. Produção científica em administração de empresas: provocação, insinuações e contribuições para um debate local. In: ENCONTRO DA ASSOCIAÇÃO NACIONAL DOS PROGRAMAS DE PÓS-GRADUAÇÃO EM ADMINISTRAÇÃO, 22, Foz do Iguaçu, PR. Anais... Rio de Janeiro: ANPAD, 1998.

BLACKWELL, R.; MINIARD, P.; ENGEL, J. Comportamento do consumidor. São Paulo: Thomson, 2005.

BIGNETTI, L. P.; PAIVA, E. L. Estudo das citações de autores de estratégia na produção acadêmica brasileira. In: ENCONTRO DA ASSOCIAÇÃO NACIONAL DOS PROGRAMAS DE PÓS-GRADUAÇÃO EM ADMINISTRAÇÃO, 25, Salvador, BA. Anais... Rio de Janeiro: ANPAD, 2001.

BOAVA, D. L. T.; MACEDO, F. M. F. Estudo sobre a essência do empreendedorismo. In: ENCONTRO DA ASSOCIAÇÃO NACIONAL DOS PROGRAMAS DE PÓS-GRADUAÇÃO EM ADMINISTRAÇÃO, 30, Salvador, BA. Anais... Rio de Janeiro: ANPAD, 2006.

CRUZ, C.; RIBEIRO, U. Metodologia científica: teoria e prática. Rio de Janeiro: Axcel Books, 2003.

DAMKE, Elói J.; WALTER, Silvana A.; SILVA, Eduardo D. A Administração é uma ciência? reflexões epistemológicas acerca de sua cientificidade. Revista de Ciências da Administração. Florianópolis, v. 12, n. 28, p. 104-125, set./ dez., 2010.

GIGLIO, E. M.; KWASNICKA, E. L. O lugar dos consumidores nos textos sobre rede. In: ENCONTRO DA ASSOCIAÇÃO NACIONAL DOS PROGRAMAS DE PÓS-GRADUAÇÃO EM ADMINISTRAÇÃO, 29, Brasília, DF. Anais... Rio de Janeiro: ANPAD, 2005.

GIGLIO, E. M.; KWASNICKA, E. L.; SANTOS, S. B. de S. Proposta de integração do consumidor na teoria e prática de redes. In: ENCONTRO DA ASSOCIAÇÃO NACIONAL DOS PROGRAMAS DE PÓS-GRADUAÇÃO EM ADMINISTRAÇÃO, 30, Salvador, BA. Anais... Rio de Janeiro: ANPAD, 2006.

HAIR JR; J. F.; BABIN, B.; MONEY, A. H.; SAMOUEL, P. Fundamentos de métodos de pesquisa em administração. Porto Alegre: Bookman, 2005. 
JUNG, C. F. Metodologia para pesquisa e desenvolvimento: aplicada a novas tecnologias, produtos e processos. Rio de Janeiro: Axcel Books, 2004.

KUHN, T. S. The copernican revolution. Cambridge: Harvard University Press, 1957.

. The structure of scientific revolutions. Chicago: University of Chicago Press, 1962.

MACHADO-DA-SILVA, C. L.; CUNHA, V. C. da; AMBONI, N. Organizações: o estado da arte da produção acadêmica no Brasil. In: ENCONTRO ANUAL DA ASSOCIAÇÃO NACIONAL DE PÓS-GRADUAÇÃO E PESQUISA EM ADMINISTRAÇÃO, 14, 1990, Florianópolis. Anais... Florianópolis: ANPAD, 1990. v. 6. p. 11-28.

MACIAS-CHAPULA, C. A. O papel da informetria e da cienciometria e sua perspectiva nacional e internacional. Ciência da Informação, v. 27, n. 2, p. 64-68, 1998.

MARTINS, G. A. Epistemologia da pesquisa em administração. In: Encontro Anual CLADEA - Reunião do Conselho de escolas de Administração; Santiago, Chile - Setembro, 1996.

MENDONÇA, A. L. de O.; VIDEIRA, A. A. P. A revolução de Kuhn. Ciência Hoje, v. 32, n. 189, p. 77-79, dez. 2002.

MORAES, R. Análise de conteúdo. Educação: Revista da Faculdade de Educação. Porto Alegre: PUCRS, v. 22, n. 37, p. 7-31, mar., 1999.

RODRIGUES, M. T. O fenômeno do empreendedorismo $e$ as teorias organizacionais: identificando a interseção teórica dos domínios. In: ENCONTRO DA ASSOCIAÇÃO NACIONAL DOS PROGRAMAS DE PÓS-GRADUAÇÃO EM ADMINISTRAÇÃO, 31, Rio de Janeiro, RJ. Anais... Rio de Janeiro: ANPAD, 2007.

SANTOS, Silvio A. dos. Existem paradigmas em administração? uma análise sobre o uso do conceito. In: INTERNATIONAL CONFERENCE IBEROAMERICAN ACADEMY OF MANAGEMENT, 3, 2003, São Paulo. Anais...2003. 
SANTOS, L. L. da S.; PINTO, M. de R. Fenomenologia, Interacionismo Simbólico e Grounded Theory: um possível arcabouço epistemológico-metodológico interpretacionista para a pesquisa em administração? In: ENCONTRO DA ASSOCIAÇÃO NACIONAL DOS PROGRAMAS DE PÓS-GRADUAÇÃO EM ADMINISTRAÇÃO, Rio de Janeiro, RJ. Anais... Rio de Janeiro: ANPAD, 2007.

THOMPSON, J. D. On building an administrative science. Administrative Science Quarterly, v. 1, n. 1, p. 102-111, 1956.

TONDOLO, V. A. G.; BITENCOURT, C. C. Uma perspectiva baseada em recursos no agronegócio cooperativo: o caso CCGL. In: ENCONTRO DA ASSOCIAÇÃO NACIONAL DOS PROGRAMAS DE PÓS-GRADUAÇÃO EM ADMINISTRAÇÃO, 29, Brasília, DF. Anais... Rio de Janeiro: ANPAD, 2005.

VERGARA, S. C.; PINTO, M. C. S. Nacionalidade das referências teóricas em análise organizacional: um estudo das nacionalidades dos autores referenciais na literatura brasileira. In: ENCONTRO DE ESTUDOS ORGANIZACIONAIS, 1, Curitiba, PR. Anais... 2000. 